\title{
Evaluation of the antiproliferative effect of Iso- mukaadial acetate on breast and ovarian cancer cells
}

Portia P Raphela-Choma ( $\sim$ portiapheladi22@gmail.com )

University of Johannesburg

Mthokozisi BC Simelane

University of Johannesburg

Mpho S Choene

University of Johannesburg

\section{Research}

Keywords: Breast cancer, Ovarian cancer, Anticancer, Apoptosis, Iso-mukaadial acetate

Posted Date: June 30th, 2021

DOl: https://doi.org/10.21203/rs.3.rs-639116/v1

License: (c) (i) This work is licensed under a Creative Commons Attribution 4.0 International License.

Read Full License 


\section{Abstract}

Background Natural compounds derived from various medicinal plants may activate several physiological pathways which can be valuable to diseases such as cancer. Isomukaadial acetate has previously been shown to possess antimalarial and anti-diabetic properties. The purpose of this study was to evaluate the antiproliferative effects of isomukaadial acetate on breast and ovarian cancer cell lines. Method Cell viability assays were conducted using AlamarBlue assay and xCELLigence system. Cell apoptosis and cell cycle arrest were determined and analyzed by flow cytometer. Effector caspase $(3 / 7)$ activation was evaluated by caspase $\mathrm{Glo} \otimes-3 / 7$ reagent and gene expression was analyzed by RealTime Polymerase Chain Reaction. Results The Alamar blue assay and XCELLigence showed that Isomukaadial acetate exhibited anti-proliferative effects on MDA-MB 231, RMG-1, and HEK 293 cell lines in a concentration-dependent manner. Iso-mukaadial acetate induced apoptosis in both cancer cell lines caused cell cycle arrest at the S phase (RMG-1) and early G2 phase (MDA-MB 231) and expressed caspase 3/7 activity in MDA-MB 231 and RMG-1 cells. BAX and p21 were upregulated in MDA-MB 231 and RMG-1 cells after treatment. Conclusion IMA significantly inhibited cancer growth and induced cell apoptosis with cell cycle modulation. IMA may be considered a promising candidate for the development of anticancer drugs either for its cytotoxic or cytostatic effect Furthermore, IMA requires to be further studied more to clearly understand its mechanism of action on cancer cells.

\section{Full Text}

This preprint is available for download as a PDF. 